\title{
Significado e impacto da Função Apoio em Atenção Básica: uma análise em situação de desastre
}

\author{
Daniela Aline Kaufmann Seady ${ }^{1}$, Manoela Fonseca Lüdtke², Vânia Maria Fighera Olivo³
}

\begin{abstract}
RESUMO
A Função Apoio é um dos principais dispositivos da Política Nacional de Humanização. Em situações de desastre torna-se ainda mais relevante. Logo após o desastre ocorrido em uma casa noturna na cidade de Santa Maria/RS, organizou-se o Grupo de Trabalho Atenção Básica e Redes (GT ABR), o qual realizou apoio às equipes de Atenção Básica. Este artigo objetiva analisar o significado e 0 impacto da Função Apoio enquanto estratégia de enfrentamento em situações de desastre. Foram entrevistados profissionais da saúde que atuaram na Atenção Básica e que receberam o apoio do Grupo de Trabalho. Os dados foram analisados por meio da Análise de Conteúdo, resultando na produção de cinco unidades de significado. Concluiu-se que o Grupo de Trabalho mostrou-se capaz de gerar reflexões no processo de trabalho, transformações nos modos de atuação profissional e articulação da rede de serviços, produzindo significativos impactos para 0 sistema de saúde.
\end{abstract}

Descritores: Apoio Social; Desastres Provocados pelo Homem; Atenção Primária à Saúde.

\section{Meaning and effect of Support Function in Primary Care: an analysis in disaster situation}

\begin{abstract}
The support function is one of the main devices of the National Humanization Policy. In disaster situations becomes even more relevant. Soon after the disaster occurred in a nightclub in the city of Santa Maria / RS, it was formed the Working Group and Primary Care Networks (GT $A B R$ ), which held support for primary care teams. This article aims to analyze the meaning and impact of support function while coping strategy in disaster situations. The Health professionals, who worked in primary care and received the support of the Working Group, were interviewed. The data were analyzed using content analysis, resulting in the production of five units of meaning. It was concluded that the Working Group has shown itself capable of generating reflections in the work process, transformations in the ways of professional practice and articulation of network services, producing significant impacts on the health system.
\end{abstract}

Descriptors: Social Support; Man-Made Disasters; Primary Health Care.

\footnotetext{
${ }^{1}$ Fisioterapeuta e Residente do Programa de Residência Multiprofissional Integrada em Saúde com ênfase em Atenção Básica/Estratégia de Saúde da Família da Universidade Federal de Santa Maria (UFSM), Santa Maria, RS, Brasil.

${ }^{2}$ Especialista em Saúde Mental pelo Programa de Residência Multiprofissional Integrada em Saúde Mental no Sistema Público de Saúde da Universidade Federal de Santa Maria (UFSM), Santa Maria, RS, Brasil.

${ }^{3}$ Doutora em Administração pela Universidade Federal do Rio Grande do Sul (UFRGS), Porto Alegre, RS, Brasil.
} 


\section{Introdução}

A Política Nacional de Humanização (PNH) surgiu sob os efeitos da $11^{\text {a }}$ Conferência Nacional de Saúde, realizada em 2000, e sinalizava a necessidade de orientação e respaldo metodológico que indicassem modos de como tornar realidade os princípios e diretrizes do Sistema Único de Saúde (SUS), prescritos na sua base jurídico-legal. Um dos principais dispositivos da PNH é a Função Apoio por ser essencial para a instauração de processos de mudança em grupos e organizações ${ }^{1}$. Esse dispositivo busca ampliar a capacidade de reflexão, de entendimento e de análise de coletivos no sentido de qualificar sua própria intervenção, sua capacidade de ofertar uma assistência à saúde de modo efetivo².

O termo "apoio" sugere uma maneira de exercer uma relação horizontal mediante a construção de várias linhas de transversalidade, ou seja, sugere uma metodologia para ordenar a relação entre equipe de referência e especialista não mais com base na autoridade, mas com base em procedimentos dialógicos. 0 apoiador procura construir, de maneira compartilhada com os outros interlocutores, projetos de intervenção, valendo-se de ofertas originárias de seu núcleo de conhecimento, de sua experiência e visão de mundo, bem como, incorporando demandas trazidas pelo outro, também em função de seu conhecimento, desejo, interesses e visão de mundo ${ }^{3}$.

A Função Apoio torna-se ainda mais relevante em situações de desastres, as quais exigem intervenções coletivas que transcendam os modos de atuação convencional dos serviços de saúde. Desastres, acidentes, catástrofes, tragédias são termos que têm significados distintos, mas que são usualmente utilizados como sinônimos. Nesse sentido, convém referenciar melhor o termo "desastre", pois é considerado o que mais se adequa ao objeto deste estudo. Um desastre é considerado uma séria interrupção no funcionamento de uma comunidade ou sociedade, ocasionando uma grande quantidade de mortes e perdas materiais, econômicas e ambientais que excedem a capacidade da comunidade ou sociedade afetada para fazer frente à situação mediante o uso de seus próprios recursos ${ }^{4}$. Assim, o desastre deve ser entendido como um processo que mede a capacidade de um núcleo social para enfrentar com êxito suas emergências em que sobrepassam a capacidade da comunidade e a obrigam a solicitar assistência dos níveis superiores ${ }^{5}$.

Essas situações desestruturam a vida de uma coletividade de forma violenta e traumatizante, temporária e/ou definitivamente. Exigem ações e respostas humanas organizadas de modo a refletir a consciência alcançada pelos profissionais de saúde e pelas autoridades em geral sobre a complexidade específica da situação e sobre a necessidade de abordá-la na maior quantidade de aspectos possíveis das áreas do conhecimento humano ${ }^{6}$.

O desastre ocorrido em janeiro de 2013, em uma casa noturna na cidade de Santa Maria/RS, em que um incêndio vitimou, de forma fatal, cerca de 240 pessoas, sendo a maioria jovens universitários, apresentou-se de forma distinta da natureza de outros e pode ser classificado como humano ou antropogênico, ou seja, provocado por ações ou omissões humanas $^{7}$. Segundo o Relatório Final da Polícia Civil de Santa Maria, a causa das mortes, em sua totalidade, ocorreu por asfixia em decorrência da fumaça tóxica produzida pelo incêndio. Além dos mortos, centenas de indivíduos sofreram lesões corporais e tiveram a necessidade de assistência hospitalar e reabilitação de longa duração, devido à gravidade das lesões e à toxidade da fumaça inaladå.

Diante do lamentável ocorrido, os serviços de saúde da Atenção Básica (AB) assumem uma função importante na coordenação do cuidado à população afetada por meio do acompanhamento longitudinal dos casos (sobreviventes, familiares e comunidade em geral), compartilhamento do cuidado e ordenação de redes de atenção à saúde, entre outros $^{9}$. Na maioria dos desastres, as ações são realizadas no improviso, unindo forças de voluntariados ${ }^{10}$. Tal situação foi também vivenciada no cenário deste estudo. Entretanto, a PNH e outras frentes como a Força Nacional do SUS e os Médicos Sem Fronteirasse se propuseram a assessorar, por meio de consultores e apoiadores, a organização emergencial das instituições e serviços envolvidos, propondo a organização de grupos de trabalho para enfrentamento da crise ${ }^{2}$. No caso deste estudo, estruturou-se, entre outras frentes emergenciais, o Grupo de Trabalho Atenção Básica e Redes (GT ABR), a partir do método do apoio institucional, proposto por Campos ${ }^{11}$. Convém esclarecer que são muitas as terminologias utilizadas para descrever os tipos metodológicos do Apoio: Apoio Matricial, Apoio Institucional e Apoio à Gestão. É importante ressaltar que nas intervenções deste estudo utilizou-se o termo Função Apoio para descrever 0 Apoio prestado à Atenção Básica após o desastre.

O Grupo de Trabalho Atenção Básica e Redes foi instituído imediatamente após o desastre, sendo composto por Apoiadores: Residentes do Programa de Residência Multiprofissional da Universidade Federal de Santa Maria (UFSM) nas áreas da Saúde Mental e Atenção Básica, trabalhadores da Secretaria da Assistência Social e da Secretaria da Saúde de Santa Maria, consultores e apoiadores da Política Nacional de Humanização (PNH), trabalhadores de Blumenau/SC e 
de São Lourenço do Sul/RS (profissionais com experiência em enfrentamento de situação de desastre) e voluntários. Destaca-se ainda que este Grupo de Trabalho realizou visitas/encontros com todas as Unidades Básicas de Saúde de Santa Maria, totalizando 27 (Unidade Básica de Saúde/Estratégia Saúde da Família), sendo efetivado, no mínimo, três encontros com cada Unidade.

A proposta deste Grupo de Trabalho foi de fortalecer as equipes nos seus respectivos territórios da rede básica para garantir a continuidade do cuidado longitudinal às vítimas envolvidas diretas ou indiretamente com o desastre. Entretanto, questionase: como a Função Apoio auxiliou essa modalidade de estruturação e quais as respostas da Atenção Básica? A Função Apoio fomentou o compartilhamento do cuidado e mudanças nos processos de trabalho? Foi possível construir redes de atenção?

Levando esses questionamentos em conta, os desastres, apesar de serem vistos como momentos de ruptura da "normalidade", também devem ser vistos como momentos de reflexão e de estudos que possam vir a contribuir para 0 avanço da sociedade. Para tanto, a análise científica do processo vivido a partir de tais ações torna-se essencial, pois permite 0 aprimoramento e a produção de conhecimentos para qualificar o sistema público de saúde.

Considerando o exposto acima, este estudo tem como objetivo analisar o significado e o impacto da Função Apoio nas equipes da Atenção Básica enquanto estratégia de enfrentamento em situações de desastre. Destaca-se ainda que esta pesquisa faz parte de um projeto guarda-chuva intitulado "A análise da estruturação de grupos de apoio às equipes da rede básica de saúde em situações de desastre: o caso de Santa Maria/RS".

\section{Metodologia}

O estudo realizado teve um caráter exploratório-descritivo, com abordagem qualitativa, na perspectiva de analisar 0 significado e o impacto da Função Apoio nas equipes de Atenção Básica. O estudo exploratório permite ao investigador um planejamento cuidadoso do método a ser utilizado, formulando o problema, as hipóteses e o registro sistemático dos dados coletados, o que possibilita a análise e a interpretação dos fenômenos com a maior exatidão possível ${ }^{12}$.

Os participantes deste estudo foram profissionais de saúde que atuam nas Unidades Básicas de Saúde/Estratégia de Saúde da Família e o critério de inclusão desse grupo foi selecionar um profissional por região administrativa do município, totalizando oito profissionais, lotados em UBS/ESF da região que apresentou maior número de óbitos em seu território (em decorrência do desastre), que receberam o Apoio do Grupo de Trabalho Atenção Básica e Redes. As classes profissionais entrevistadas foram: Enfermagem, Técnico em Enfermagem, Medicina e Agente Comunitário de Saúde. Os profissionais foram tratados como letras e números, respectivamente, para manter o sigilo da identidade dos mesmos. A utilização das informações para fins de pesquisa estão em conformidade com a Resolução nº 466/2012 do Conselho Nacional de Saúde (CNS) ${ }^{13}$.

A coleta dos dados foi realizada no período de outubro a novembro de 2013 , ou seja, transcorrido nove a dez meses do desastre. Utilizou-se como instrumento um roteiro de entrevista semiestruturado. As entrevistas foram gravadas digitalmente e transcritas pela pesquisadora. A transcrição das entrevistas foi textual, ou seja, procurou-se, do modo mais fiel possível, escrever tal e qual foi falado pelos participantes, utilizando as simbologias para demarcar determinadas reações ou acontecimentos, como as reticências para demonstrar silêncios. A etapa seguinte do trabalho foi a sistematização, compreensão e interpretação dos depoimentos, amparados à luz dos referenciais teóricos ${ }^{14,15}$.

A pesquisa foi aprovada pelo Comitê de Ética em Pesquisa da Universidade Federal de Santa Maria (em 25/07/2013, registro $0 \mathrm{~N}^{0} 347.241$ ).

\section{Resultados e discussão}

Por meio desse estudo foi possível identificar e classificar as unidades de análise em cinco categorias, nomeadas segundo 0 conteúdo que revelaram: Compreensão da Função Apoio; Qualificação do Cuidado: a Clínica Ampliada e Compartilhada; Reflexão sobre os processos de trabalho; Transformações nos modos de atuação profissional e Tecendo redes: conexões necessárias.

\section{Compreensão da Função Apoio}

A constituição do Apoio Paidéia fundamenta-se em teorias e práticas que procuram articular o campo da política e da gestão com saberes e experiências originários da psicanálise, da pedagogia e da análise institucional ${ }^{16}$. 0 Apoio Paidéia é uma postura metodológica que busca reformular os tradicionais mecanismos de gestão. O Apoio sugere que tanto 
na gestão do trabalho em equipe quanto na clínica, na saúde pública ou nos processos pedagógicos, a relação entre sujeitos com saberes, valores e papéis distintos pode ocorrer de maneira dialógica. Além disso, o Apoio oferece retaguarda assistencial especializada e suporte técnico-pedagógico para equipes e profissionais encarregados da atenção aos problemas de saúde ${ }^{3,11}$.

Corroborando essa ideia, o objetivo da Função Apoio logo após o desastre foi o de aproximar-se da Atenção Básica, colocando o apoiador ao lado da equipe para juntos compartilhar os casos, por meio da corresponsabilização e construção/ integração da rede de serviços de saúde. Como esse dispositivo não era utilizado na rede de serviços do Município de forma sistematizada pode-se inferir que a Função Apoio foi uma experiência inovadora, instituída em decorrência do desastre. $O$ significado desse Apoio é apreendido por meio dos fragmentos a seguir:

Eu entendi que eles [Apoio] vieram auxiliar a gente como acolher os familiares, como encaminhar e também ver se a gente precisava de ajuda. Nós tivemos vários casos que procuraram ajuda na Unidade, pacientes e familiares [...] Eles [Apoio] vieram para isto, para ajudar a gente a entender a como receber este pessoal. O que podíamos fazer, se oferecer para ir visitá-los se os familiares procurassem ajuda, e para onde a gente iria encaminhar. (E4)

Eles [Apoio] vieram para apoiar, formaram uma rede aqui dentro, de profissionais da Unidade que fossem captar os usuários em sofrimento que tivessem relação com o evento. Foi um suporte para a equipe organizar o processo de trabalho diante desse novo cenário. (E8)

É interessante perceber que o Apoio prestado a $\mathrm{AB}$ teve a compreensão dos objetivos propostos, além de ser catalisador de reflexões e estratégias sobre o significado e os modos de acolhimento e cuidado às vítimas. $O$ Apoio é produzido nas relações horizontais com o intuito de ampliar a potência de pensar, de agir e de conhecer das pessoas envolvidas nesse processo ${ }^{17}$.

Feitas essas considerações, percebe-se que houve entendimento dos objetivos e da finalidade da Função Apoio prestada às Unidades de Saúde. O Apoio foi visto como um auxílio para as equipes pensarem e organizarem o cuidado que seria prestado às vítimas, aos familiares e à comunidade em geral atingida pelo desastre.

\section{Qualificação do cuidado: a clínica ampliada e compartilhada}

Aestratégia de Apoio é uma ferramenta de qualificação do cuidado que incentiva a prática da clínica ampliada e compartilhada. O Apoio efetiva-se com o acompanhamento da construção dos percursos, uma vez que apoiar não é fazer pelo outro, mas, sim, colocar-se ao lado e firmar a potência criadora do humano ${ }^{18}$. O momento fulcral no processo de reflexividade social, face aos desastres, é a fase de reconstrução. Após situações de desastres, a Atenção Básica torna-se um nível de saúde de suma relevância para o cuidado à saúde dos envolvidos. A Função Apoio pode ser um auxílio especializado no enfrentamento de dificuldades que permeiam o cotidiano dos serviços de saúde, além de desenvolver possibilidades da clínica ampliada.

A proposta da clínica ampliada busca constituir-se em uma ferramenta de articulação e inclusão dos diferentes enfoques (o biomédico, o social e o psicológico), ou seja, traduz-se numa ampliação do objeto de trabalho e na busca de resultados eficientes, com inclusão de novos instrumentos ${ }^{19}$. Nesta perspectiva, para prestar um cuidado integral às vítimas do desastre, foi necessário agregar conhecimentos interdisciplinares, como pode ser observado no recorte a seguir.

Quando iam discutir um caso, todo mundo escutava a opinião de todo mundo, eu vi caso a caso e que a minha opinião podia trazer algum proveito para aquela pessoa. Se somou todo aquele conhecimento com o objetivo comum de beneficiar aquela pessoa, não houve disputa de conhecimentos, e sim soma. O que a gente observava antes era a disputa do conhecimento. (E1)

O Apoio incentivou a equipe a utilizar uma metodologia dialógica não só para discutir casos e traçar estratégias como nos projetos terapêuticos individuais, mas também ajudou a equipe a repensar o modelo de atuação e os processos de trabalho. (E3)

Somando-se a isso, outro aspecto relevante na qualificação do cuidado está relacionado com a clínica compartilhada. A tecnologia proposta pela PNH admite que a complexidade da clínica, especialmente em situações de desastre, deve significar o reconhecimento da necessidade de compartilhar diagnósticos de problemas e propostas de soluções, pois se aposta que aprender a fazer algo de forma compartilhada é infinitamente mais potente do que insistir em uma abordagem 
pontual e individual ${ }^{19}$. Para haver compartilhamento do cuidado percebeu-se que os apoiadores necessitavam conhecer os casos, o contexto no território. Para isso, o Grupo de Trabalho Atenção Básica e Redes utilizava uma estratégia interessante: antes de realizar os encontros junto às equipes da Atenção Básica, buscavam informações nos prontuários e discutiam os casos com outros profissionais do Serviço de Atenção Psicossocial, no caso, em especial o "Acolhimento 24 horas" às vitimas - serviço instituído imediatamente após o desastre. Essa dinâmica tinha a finalidade de identificar os casos dos territórios a serem visitados e reconhecer os que exigiam maior atenção e intervenção. As informações eram levadas e discutidas com as equipes de saúde da $A B$, tendo em vista a qualificação, o compartilhamento do cuidado, bem como o desencadeamento do processo de integração com a rede de serviços do território onde residia o usuário. Com base nisso, os apoiadores contribuíam na elaboração de Projeto Terapêutico Singular, pautados em tecnologias de clínica ampliada e compartilhada, acolhimento, encaminhamentos, escuta qualificada, vínculos e afetos, além de outros $^{19}$. Por meio das falas dos entrevistados percebe-se que a Função Apoio incentivou o desenvolvimento da clínica ampliada e compartilhada. Na ótica de um dos entrevistados:

O Apoio me serviu no sentido de me localizar no território de atuação e de conhecer a contextualização dessas famílias que a gente não conhecia. A gente não faz visita, não tem informação sobre a realidade, o contexto que essas pessoas vivem. Com o que o grupo [Apoio] me possibilitou, ficou muito mais fácil de conseguir acompanhar essas familias, já sabia um pouco da história, nesse sentido para mim foi o diferencial. (E7)

Outro aspecto da Função Apoio na qualificação do cuidado no sentido da clínica está na construção do vínculo da equipe com o usuário, sendo tal conexão primordial para a prestação de um atendimento pautado na integralidade da atenção à saúde. A noção de vínculo faz refletir sobre a responsabilidade e o compromisso, onde criar vínculos implica ter relações tão próximas e tão claras com os usuários, que o profissional se sensibiliza com todo o sofrimento daquele outro, sentindo-se responsável pela vida e morte do usuário, possibilitando uma intervenção nem burocrática e nem impessoal ${ }^{20}$.

O vínculo torna-se ainda mais relevante após situações de desastres, pois o universo material, físico e emocional da população requer atenção, durante um período prolongado, às pessoas mais afetadas, as quais necessitam reconstruir suas vidas. Os profissionais de saúde devem intervir na saúde desses sujeitos visando o restabelecimento da integridade psicológica e do equilíbrio das redes sociais, sob risco de o sofrimento psíquico tornar-se crônico e retardar o processo de recuperação das perdas emocionais causadas pelo desastre 9 . Pode-se perceber, no fragmento a seguir, o impacto da Função Apoio com a efetivação do vínculo.

A gente marcava o horário aqui [na Unidade] e eles vinham [usuários]. E depois deste primeiro contato, eles vinham, praticamente que toda semana. Foi criado um vínculo e eles vinham toda semana. Então a gente entendeu como uma criação de vínculo mesmo, porque senão eles teriam vindo uma vez e não teriam voltado mais. (E7)

A partir deste recorte foi possível entender que a Função Apoio fomentou a construção do vínculo que envolve afetividade, ajuda e respeito, estimula a autonomia e a cidadania ${ }^{21}$.

\section{Reflexão sobre os processos de trabalho}

Processos de trabalho são processos de produção/constituição de sujeitos. Esses processos podem ser efetivados pela PNH a fim de ajudar a disparar movimentos e assumir suas consequências por meio do Apoio ${ }^{11,16}$ no sentido de intervençãooferta para ajudar a redefinir a compreensão do serviço e de suas bases de organização ${ }^{22}$. Para tanto, faz-se necessário ampliar a capacidade de reflexão crítica. Contudo, o grau de dificuldade desta reflexão aumenta com a complexidade e com a indeterminação dos processos de trabalho ${ }^{23}$. Num contexto de desastre em que as equipes necessitam dar respostas às novas demandas não convencionais torna-se imprescindível olhar o processo de trabalho e analisar o mesmo.

Eu disse 'olha gente, acho que vocês estão querendo demais da gente', 'vocês querem que a gente vá dar apoio se a gente aqui está totalmente desestruturada? [...] Vamos ter que sair da Unidade para dar apoio sendo que a gente não está se sentindo capaz de fazer isso e não tem nem estrutura pra ti poder sair do posto de saúde porque a cada pouco chega um, dois pacientes passando mal. Como é que tu vai dizer agora vou fazer umas visitas, vou dar apoio pro pessoal?' (E5) 
No recorte da fala supracitada percebem-se as fragilidades dos processos de trabalho. A fragmentação do trabalho dá-se em meio a uma contradição que se expressa no embate entre novos modelos de atenção-gestão que implicam processos de trabalho pautados no diálogo ${ }^{22}$. Porém há uma cultura da comunicação vertical e estilo de gestão que não fomenta momentos para comunicação-análise do fazer, dificultando uma inovação no âmbito da atenção ao usuário, principalmente frente a demandas emergenciais, pois é o momento em que as limitações e incoerências de um sistema complexo vêm à tona ${ }^{10}$.

Nesse contexto, o Apoio foi uma estratégia metodológica, pois apostou na realização de encontros por meio de rodas de conversa, na escuta das necessidades, de forma coletiva, na identificação de alternativas e possibilidades de atuação frente à situação daquele momento específico. A Função Apoio instigou a ampliação da capacidade de análise da Atenção Básica frente às dificuldades, além de potencializar e implicar os mesmos para que, mesmo diante das fragilidades, fossem pactuadas novas práticas e modos de agir necessários em função da situação instalada a partir do desastre. Contudo, deve-se ressaltar que há obstáculos na própria maneira como a Atenção Básica vem se estruturando, os quais conspiram contra o modo interdisciplinar e dialógico de se operar. De um modo geral, a lógica que ainda orienta a atual produção de saúde na Atenção Básica é devedora do modelo hegemônico com enfoque biomédico. O grande desafio é a organização do trabalho em saúde que busque romper com a dinâmica médico-centrada, do modelo hegemônico de organização e forma de trabalho da equipe ${ }^{24}$.

Analisando mais profundamente as limitações do processo de trabalho, a partir de sua interface com a Função Apoio, percebese a dificuldade na comunicação da equipe. Em algumas Unidades entrevistadas foi relatado que realizar reuniões de equipe não é uma prática do serviço. Essa falta de reunião torna quase impossível a integração comunicativa das abordagens diagnósticas e terapêuticas, compromete a clínica ampliada, assim como o trabalho interdisciplinar e a melhoria no processo de trabalho.

A gente na UBS tem que ser muito criativo para dar conta e atender bem nossos usuários [...] a gente não sabe quem são os nossos usuários, não tem indicadores. [...] Na verdade a gente não tem nem reunião de equipe. Para ter uma ideia, reunião de equipe, teve há cinco anos a última. (E7)

Assim, percebe-se que a circulação de informações, os contatos interprofissionais e a preocupação com o sujeito como um todo ainda são entraves no modelo tradicional de estruturação do poder em organizações de saúde. Há agrupamentos de profissionais em vez de equipes multidisciplinares e interdisciplinares. A partir dos encontros com os Apoiadores, as equipes foram convidadas a repensar algumas questões de sua prática e de seus mecanismos de gestão (enfrentamento dos problemas de gestão), com vistas a dar conta daquilo a que o Apoio se propôs. Nesse panorama, 0 Grupo de Trabalho Atenção Básica e Redes construiu um espaço de reflexão, tornando possível pensar novos modos de produção de cuidado, inovar as práticas, incentivar e impulsionar a autonomia dos profissionais a partir da compreensão do seu próprio processo de trabalho. O Apoio fomentou a reflexão sobre a qualidade e a existência de espaços coletivos, do estabelecimento de algum grau de cogestão ou de democracia institucional, destacando que estes são elementos essenciais para o êxito do desenvolvimento desse método de Apoio a um serviço ${ }^{3}$.

\section{Transformações nos modos de atuação profissional}

Apesar da complexidade que envolve mudanças no processo de trabalho, estas não ocorrerão se não houver a transformação do profissional. Colocar os processos de trabalho em análise não se dissocia de uma perspectiva de intervenção, já que fomenta e potencializa movimentos, desvios e rupturas que sugerem transformar os modos de trabalhar e de ser no trabalho22. A intervenção da Função Apoio produz transformações na prática profissional e nos modos de produção de saúde, afirmando a clínica e a gestão como campo de saberes e práticas indissociáveis ${ }^{16,25}$, como pode ser visto na fala abaixo.

Depois que vieram aqui [o Apoio], abriu setenta por cento meu entendimento, me senti com mais firmeza de chegar nas casas, de trabalhar, não só nos casos das vítimas, nas outras casas que tem outros problemas. (E6)

Olha, o que mais me surtiu efeito é que quando acontece uma tragédia existe a necessidade de ter iniciativas em relação àquilo que está acontecendo [...] eu dei importância porque alguém se mobilizou [...], penso que é por aí o caminho. É fazer visita, é prestar acolhimento, prestar a escuta. A gente faz isso no dia-a-dia, mas numa tragédia às vezes as pessoas se fecham e daí tu tem que ir a busca dessas pessoas pra que elas venham até você. (E5) 
Por meio destas falas são notórias as contribuições da Função Apoio na percepção sobre o modo de atuação profissional. O Apoio mobiliza os trabalhadores para a utilização de ferramentas de uma atenção mais humanizada preconizada pela $\mathrm{PNH}^{22}$. Isso se torna mais relevante em situações de calamidade pública, pois exigem respostas às novas demandas, como visto no fragmento a seguir:

[...] a questão assim de como a gente ia se dirigir para estas pessoas, neste momento foi muito complicado porque a gente não tem formação para trabalhar em situações de calamidade pública, em situação de desastre. Não tinha uma leitura, não tinha experiência, nem vivência. [Na recepção] cada vez que chegava para nós era um impacto e ao mesmo tempo gerava muita ansiedade de quem prestava o Apoio. (E7)

Contabilizo assim, uns 10 anos de amadurecimento profissional. (E1)

A partir desses recortes foi possível perceber que apoiar estas equipes não se focava apenas na construção de percursos de enfrentamento frente à situação do desastre, sendo também uma estratégia utilizada para viabilizar mobilização interna das equipes, possibilitando autorreflexão sobre os modos de agir. Percebe-se que o enfrentamento da situação do desastre, a partir do auxílio do Apoio, deixou um legado imaterial aos profissionais de saúde, conhecimentos intelectuais e ricas experiências profissionais produzidas em momentos de forte tensão.

\section{Tecendo redes: conexões necessárias}

Outro desafio da Função Apoio foi fomentar a construção de um trabalho em rede integrada de saúde, pois sabe-se que o trabalho articulado em rede é fundamental para garantir acesso universal dos usuários aos serviços e às ações de saúde e oferecer atenção integral, não somente aos usuários com relação direta ou indireta com o desastre, mas, sim, a todos os usuários ${ }^{26}$. Desde o início da construção do SUS trabalhar em redes integradas de saúde é um desafio. Redes, em essência, correspondem à articulação entre serviços e sistemas de saúde e às relações entre atores que nela atuam, mediante relações de interdependência entre os pontos da rede.

Um novo desenho do SUS, com vistas à constituição de uma rede de atenção, está relacionado à possibilidade de formação de pessoas com capacidade para articular diferentes espaços de governo, respeitando a autonomia e a legitimidade local e, ao mesmo tempo, inserindo-se na disputa pela conformação dos modelos de atenção e das próprias características das redes de atenção locais ${ }^{27}$. Um aspecto marcante que se pôde perceber no impacto da Função Apoio foi a formação de redes de atenção à saúde, pois um dos seus objetivos era desencadear processos de construção de redes por meio da interlocução dos diferentes pontos e níveis de atenção: Serviço de Atenção Psicossocial - Acolhimento 24 horas e outros, Atenção Básica, Sistema Único de Assistência Social (SUAS), Centro de Referência em Saúde do Trabalhador (CEREST), hospitais, bem como outras redes intersetoriais. Por meio do fragmento abaixo, percebe-se que a Função Apoio possibilitou maior integração com outros serviços da rede.

Sim, nossa! A rede nunca funcionou tão bem! Foi um momento que a burocracia foi colocada de lado e fizemos funcionar e funcionou! Foi um momento em que as Unidades estavam todas interligadas, a gente referenciando pacientes para outras Unidades, as outras Unidades referenciando para nós. (E1)

Acredito que através do Apoio a gente teve um maior conhecimento de como funcionava o serviço de saúde mental, entender qual era o fluxograma, como e para onde eu encaminho estes pacientes e como é que eles vão ser atendidos. Eu acho que teve ampla divulgação neste sentido. E realmente tudo foi muito bem viabilizado, todos os encaminhamentos que a gente fazia, não havia entrave nenhum [...] foi isto que o Apoio nos trouxe, de mostrar qual era o fluxo, os atendimentos, para que servia cada serviço. (E7)

Tendo em vista estas abordagens, percebe-se que a proposta da Função Apoio proporcionou a possibilidade de conexões necessárias para tecer redes de saúde. O Apoio realizado por meio de encontros presenciais possibilitou um contato mais próximo com os profissionais de saúde, pois se acredita que uma rede afetiva torne-se efetiva. Essa prática está em consonância com o Ministério da Saúde, o qual afirma que a organização das políticas públicas em rede é um requisito para a produção de saúde e que depende da organização do sistema de saúde e da integração das ações intersetoriais de um território ${ }^{28}$. 
Os entrevistados foram unânimes sobre a necessidade de continuidade do Apoio. Pode-se concluir que este se constitui como uma importante ferramenta tecnológica disparadora de mudanças na atenção, gestão, processos de trabalho das equipes e construção/fortalecimento de redes. Assim, é notória a importância social desse estudo, pois se entende que ele poderá oferecer subsídios para pensarem-se as ações das Políticas Públicas de atenção e de formação profissional. Servirá para subsidiar respostas a situações emergenciais e para evidenciar o quanto as equipes precisam parar para refletir seu processo de trabalho em situações cotidianas e não apenas em momentos nos quais estão pressionados por contextos catastróficos.

\section{Considerações Finais}

Verificou-se que foi possível analisar o significado, o impacto e a operacionalização da Função Apoio nas equipes da Atenção Básica enquanto estratégia de enfrentamento em situações de desastre. A Função Apoio mostrou-se capaz de ser compreendida, promover a clínica ampliada e compartilhada, gerar transformações nos modos de atuação profissional, reflexões nos processos de trabalho e articulação da rede de serviços de saúde. Além disso, potencializou a capacidade de reflexão, de entendimento e de análise de coletivos que, assim, podem qualificar sua própria intervenção, sua capacidade de produzir mais e melhor saúde.

Compreende-se que o Apoio prestado à Atenção Básica logo após uma situação de desastre, apesar de incipiente, procurou criar espaços protegidos que permitiram a interação de diferenças, construindo uma análise e uma interpretação sintética e acordando linhas de intervenção e distribuição de tarefas entre os vários sujeitos envolvidos no processo. A partir do presente estudo foi possível perceber que a Função Apoio dá-se no sentido de encontro e compartilhamento de saberes, de construção de novos olhares, dispositivos e processos de trabalho para que, a partir desse momento, seja possível vislumbrar equipes (apoiadas e de apoiadores) capazes de refletir, entender e analisar coletivos para qualificar suas intervenções. Com isso espera-se que gestores de saúde apostem na continuidade do Apoio e invistam cada vez mais neste dispositivo capaz de instaurar processos de mudanças.

A partir da análise da experiência vivida no Grupo de Trabalho Atenção Básica e Redes, pode-se inferir que houve a incorporação de novos conhecimentos, habilidades e práticas, viabilizando a relação entre atitudes críticas e reflexivas com práticas interdisciplinares na saúde, contribuindo, assim, com o surgimento de experiências alternativas de formação e atuação profissional. Destaca-se, também, o legado de conhecimentos deixados pelos Apoiadores, profissionais eticamente comprometidos com a situação de calamidade pública instalada, pessoas que estavam solidárias, moral, intelectual e socialmente envolvidas, comprometidas como o momento histórico vivido e que se doaram, sem medida, para fortalecer ações intersetoriais e parcerias, preocupadas em resguardar e reconstruir vidas.

Propõem-se novos estudos sobre a situação vivenciada, pois, além de trazer à memória o histórico de ações conjuntas da saúde e as políticas públicas voltadas à problemática dos desastres, representa a possibilidade de reviver reflexivamente a situação de emergência e seus impactos, embora se espere que jamais haja outra situação de calamidade pública semelhante.

\section{Referências Bibliográficas}

1. Brasil. Ministério da Saúde. $11^{\text {a }}$ Conferência Nacional de Saúde: efetivando o SUS: acesso, qualidade e humanização na Atenção à saúde, com controle social: relatório final. Brasília: Ministério da Saúde; 2001.

2. Brasil. Ministério da Saúde. Secretaria de Atenção à Saúde. Núcleo Técnico da Política Nacional de Humanização. HumanizaSUS: Documento base para gestores e trabalhadores do SUS. Brasília: Ministério da Saúde, 4. ed.; 2008.

3. Campos GWS, Domitti AC. Apoio matricial e equipe de referência: uma metodologia para gestão do trabalho interdisciplinar em saúde. Cad Saude Publica, Rio de Janeiro, fev 2007; 23(2):399-407.

4. López TE, Santana NP. El terremoto de 2010 en Chile: respuesta del sistema de salud y de la cooperación internacional. Rev Panam Salud Publica, 2011; 30(2):160-6.

5. Maturana A. Situaciones Catastróficas [editoriales]. Rev Chile Salud Publica, 2010; 14(1):5-7.

6. Paladino E, Thomé JT. Psicologia em tempos de tragédia. Revista Mente e Cérebro, Ed.221. [documento eletrônico]. Junho de 2011. [Acessado em 04 fev 2014]. Disponível em http://www.josethome.med.br/JoseTHOME/thomewpress/

7. Brasil. Ministério da Integração Nacional. Secretaria Nacional de Defesa Civil. Manual de Medicina de Desastres. Brasilia: Ministério da Integração Nacional de Defesa Civil, 3. Ed,; 2007. 
8. Rio Grande do Sul. SSP - Polícia Civil, Departamento de Polícia do Interior, $1^{\text {a }}$ Delegacia de Polícia de Santa Maria-RS. Relatório Final ao Meritíssimo Juiz de Direito (1 ${ }^{\text {a }}$ Vara Criminal do Fórum de Santa Maria-RS), sob o nº 94/2013/15050. [documento eletrônico]. Santa Maria-RS, 2013. [Acessado em 20 jan de 2014]. Disponível em: http://www.desaparecidos. rs.gov.br/upload/20130322165718relatorio_kiss_definitivo.pdf

9. Puel E, Thomè JT, Feuser Z. (Orgs.). 2008. Depois das chuvas... O olhar do cuidado sobre o Vale do Itajaí: coletânea de artigos sobre vivências de profissionais que atuaram no trabalho de reconstrução. Secretaria de Estado da Saúde. Florianópolis: Gerência de Coordenação da Atenção Básica, 2012.

10. Santos R. Gestão de desastres e política de assistência social: estudo de caso de Blumenau/SC. [Tese]. Doutorado em Sociologia Política. Florianópolis: Universidade Federal de Santa Catarina; 2012.

11. Campos GWS. Equipes de referência e apoio especializado matricial: um ensaio sobre a reorganização do trabalho em saúde. Cien Saude Colet, 1999, 4(2): 393-403.

12. Marconi MA, Lakatos EM. Técnicas de pesquisa: planejamento e execução de pesquisas, amostragens e técnicas de pesquisa, elaboração, análise e interpretação de dados. 4. ed. São Paulo: Atlas; 1999.

13. Brasil. Ministério da Saúde. Conselho Nacional de Saúde. Resolução n. 466/12, de 12 de dezembro de 2012. Dispõe sobre pesquisa envolvendo seres humanos. Publicada no DOU no 12 - quinta-feira, 13 de junho de 2013 - Seção 1, p. 59. Diário Oficial da União 2013; 13 jun.

14. Laville C, Dionne J. A Construção do saber: manual de metodologia da pesquisa em ciências humanas. Porto Alegre: Artes Médicas Sul Ltda.; Belo Horizonte: Editora UFMG; 1999.

15. Minayo MCS. O desafio do conhecimento: pesquisa qualitativa em saúde. 6. ed. São Paulo: Hucitec; Rio de Janeiro: Abrasco,1999. 16. Campos GWS. Um Método para Análise e Co-gestão de Coletivos: a constituição do sujeito, a produção de valor de uso e a democracia em instituições: o método da roda. 2. ed. São Paulo: Hucitec; 2005, p. 185.

17. Fernandes, FD. (In)ventando multiplicidades: a função apoio enquanto dispositivo de produção de saúde no SUS. [Monografia]. São Paulo: Programa de Aprimoramento Multiprofissional e Especialização em Saúde Coletiva - Faculdade de Medicina da Universidade de São Paulo; 2012.

18. Guedes CR, Roza MMR, Barros MEB. O apoio institucional naPolítica Nacional de Humanização: uma experiência de transformação das práticas de produção de saúde na rede de atenção básica. Cad Saude Coletiva, Rio de Janeiro, 2012; 20(1): 93-101.

19. Brasil. Ministério da saúde. Secretaria de atenção à saúde. Política nacional de Humanização da atenção e Gestão do SUS. Clínica ampliada e compartilhada. Brasília: Ministério da saúde; 2009.

20. Merhy EE. Em busca da qualidade dos serviços de saúde: os serviços de porta aberta para a saúde e o modelo tecnoassistencial em defesa da vida (ou como aproveitar os ruídos do cotidiano dos serviços de saúde e colegiadamente reorganizar o processo de trabalho na busca da qualidade das ações de saúde). In: Cecílio LCO. (Org.) Inventando a mudança em saúde. São Paulo: Hucitec; 1994. p.116-60, pp. 138.

21. Machado MFAS. Compreensão das mudanças comportamentais do usuário do PPS por meio da participação habilitadora. [Tese]. Fortaleza: Faculdade de Farmácia, Odontologia e Enfermagem, Universidade Federal do Ceará; 2007.

22. Santos Filho SB, Barros MEB, Gomes RS. A Política Nacional de Humanização como política que se faz no processo de trabalho em saúde. Interface - Comunic., Saude, Educ. 2009; 13(1): 603-13.

23. De Faria HP et al. Processo de trabalho em saúde. 2a ed. Belo Horizonte: Nescon/UFMG, Coopmed; 2009.

24. Abrahão AL. Atenção Básica e o processo de trabalho em saúde. Informe-se em promoção da saúde. 2007; 3(1): $01-03$.

25. Campos GWS. Reforma política e sanitária: a sustentabilidade do SUS em questão? Cien Saude Colet., Abr. 2007; 12(2): p. 301-306.

26. Brasil. Ministério da Saúde. CONASEMS: Rede de Atenção à Saúde. Brasília: Ministério da Saúde; 2014.

27. Righi LB. Poder local e inovação no SUS: estudo sobre a construção de redes de atenção à saúde em três municípios no Estado do Rio Grande do Sul. [Tese]. Doutorado em Saúde Coletiva. Campinas: UNICAMP; 2003.

28. Mori ME, Oliveira OVM. Os coletivos da Política Nacional de Humanização (PNH): a cogestão em ato. Interface Comunic., Saude, Educ., 2009; 13(1): 627-40. 


\section{Daniela Aline Kaufmann Seady}

Endereço para correspondência - Rua: Euclides da Cunha, n 1946, apto 106, bloco B, Edifício Titan, Bairro: Dores, CEP: 97090000, Cidade: Santa Maria, RS, Brasil.

E-mail: danielakaufmann@yahoo.com.br

Lattes: http://lattes.cnpq.br/8712624227383162

Manoela Fonseca Lüdtke - manu.ludtke@gmail.com

Vânia Maria Fighera Olivo - vania.olivo.ufsm@gmail.com

Enviado em 30 de junho de 2014.

Aceito em 25 de maio de 2015. 